\title{
O SECRETÁRIO EXECUTIVO BILÍNGUE COMO AGENTE FACILITADOR EM NEGOCIAÇÕES DO MERCOSUL
}

\section{THE EXECUTIVE SECRETARY BILINGUAL AS FACILITATOR AGENT IN NEGOTIATIONS FROM THE MERCOSUR}

\section{Helton Rafael Ferreira do Nascimento}

Graduado em Secretariado Executivo Bilíngue pela Autarquia de Ensino Superior de Garanhuns -Aesga. Especialista em Gestão de Negócios e Pessoas pela Autarquia de Ensino Superior de Garanhuns, Aesga. E-mail: elton_keep@yahoo.com.br (Brasil)

\section{Karla Janaina Alexandre da Silva}

Mestra em Linguística pela Universidade Federal de Pernambuco, UFPE.

Professora no Instituto Federal de Alagoas, IFAL e na Autarquia de Ensino Superior de Garanhuns, AESGA.

E-mail: karlajanainas@bol.com.br (Brasil) 


\section{O SECRETÁRIO EXECUTIVO BILÍNGUE COMO AGENTE FACILITADOR EM NEGOCIAÇÕES DO MERCOSUL}

\section{RESUMO}

Esteartigo tem como objetivolevar a uma reflexão sobre a possível atuação do Secretário Executivo Bilíngue (SEB), como agente facilitador na comunicação e negociação organizacional noMercosul, conjunto de habilidades técnicas, que lhes foram acrescentadas após a regulamentação da profissão com as Leis 7.377 e 9.261. Tendo em vista que todos os países componentes desse bloco, exceto o Brasil,falam espanhol e muitas empresas têm demandado de profissionais que tenham uma visão corporativa e domínio de línguas estrangeiras, como um fator chave no processo de internacionalização, apresenta-se como problemática, a seguinte questão: como o SEB, pode promover um diferencial competitivo para as organizações? Quanto a sua metodologia, optou-se pelo método dedutivo-exploratório que esclarece e modifica conceitos e ideias. Conclui-se que com as mudanças na economia mundial e a criação de blocos como o Mercosul, as empresas brasileiras necessitam de profissionais que atendam as exigências do mercado empresarial global.Por isso, o SEB está capacitado para atuar como agente facilitador em negociaçõescomerciais nesse bloco econômico, por dispor da fluência na língua espanhola e pelas suas competências gerencias.

Palavras-chave: Globalização. Mercosul. Secretário Executivo Bilíngue. 
THE EXECUTIVE SECRETARY BILINGUAL AS FACILITATOR AGENT IN NEGOTIATIONS FROM THE MERCOSUR

\begin{abstract}
This article have as objective to leave the a reflection on the possible role of the Executive Secretary Bilingual as facilitator agent in communication and business negotiation in MERCOSUR, technical abilities that have been added after the regulation of the profession with the Laws 7.377 and 9.261. Considering that all the countries from Mercosur speaks the spanish except Brazil, many companies have demanded that the professionals has a corporate vision and knowledge of foreign languages as a key factor to the internationalization process, having as problematic the following question as the Executive Secretary Bilingual may promote a competitive advantage to the companies? For the methodology it was selected the method deductive-exploratory, method that modifies and clarifies concepts and ideas. With the changes in the world economy and the creation of blocs like MERCOSUR, the brazilian companies need professionals that answer the demands of the global market. Therefore, the Executive Secretary Bilingual is prepared to act as facilitator agent in negotiations from Mercosur, by the fluency in the Spanish language and their managerial skills.
\end{abstract}

Keywords: Bilingual Executive Secretary, Globalization, Mercosur. 


\section{INTRODUÇÃO}

Uma das características da globalização é promover a integração entre países, com intuito de fortalecer a economia mundialpor meiode acordos político-econômicos; com isso, surgíramos grandes blocos comerciais que permitem que diferentes países de um mesmo continente tenham chances iguais de desenvolvimento econômico.

Na América do Sul, o Mercado Comum do Sul, doravante chamado de Mercosul, Pinheiro (2009), é tido como um dos principais blocos econômicos do mundo, composto por Brasil, Argentina, Uruguai, Venezuela e Paraguai, tendo a Bolívia, Chile, Colômbia, Equador e Peru como membros associados.

Tendo em vista que todos os países componentes deste bloco, exceto o Brasil, falam espanhol e muitas empresas nacionais comercializam seus produtos e/ou serviços, as organizações têm demandado de profissionais que tenham uma visão corporativa e domínio de línguas estrangeiras, como um fator chave de sucesso do processo de internacionalização.

Contudo, as empresas brasileiras enfrentam problemas cada vez maiores na sua cadeia de fornecimento e em suas operações produtivas, isso devido à falta de mão de obra especializada, principalmente quando se trata do processo de internacionalização, apresenta-se como problemática para este artigo a seguinte questão: como o profissional de Secretariado Executivo Bilíngue (SEB), pode promover um diferencial competitivo para essas organizações?

Para isso, essa pesquisa tem como objetivo levar a uma reflexão sobre a possível atuação do SEB como agente facilitador na comunicação e negociação organizacional no Mercosul, pelo conhecimento da língua espanhola e visão global, apoio e envolvimento nas tomadas de decisões gerenciais, habilidades estratégicaspara identificar novas oportunidades de negócios, capacidade inovadora,comprometimento com as atividades de exportação neste contingente. Conjunto de habilidades técnicas, que lhes foram acrescentadas após a regulamentação da profissão com as Leis 7.377 e 9.261 .

O espanhol além de ser a língua da maioria dos países limítrofes do Brasil, também é o idioma materno de grande parte dos países de continentes americanos e da Espanha, país que muito investe no Brasil. Esses fatores contribuem para que seu aprendizado seja uma das principais qualificações exigidas na comunicação empresarial. Por essa razão é imprescindível o domínio dessa língua para o SEB.

A elaboração desse artigo está embasada nos seguintes autores: Lacombe (2003), D’Elia, Amorim e Sita (2013),Santos (2012), Cielo, Schmidt e Kühn (2010), Pinheiro (2009), 
Bonde (2009); Sedycias (2005) e Veiga (2010), por desenvolverem pesquisas similares e compatíveis com esta linha de investigação.

Quanto a sua metodologia, essa investigação trata de uma pesquisade revisão bibliográfica. Para sua estruturação e desenvolvimento, optou-se pelo método dedutivoexploratório que esclarece e modifica conceitos e ideias, tendo em vista a formulação de problemas mais precisos ou hipóteses pesquisáveis para estudos posteriores. Com o objetivo de proporcionar visão geral, de tipo aproximativo, acerca de determinado fato.

O conteúdo encontra-se organizado em três seções, a primeiratrata da globalização e seus reflexos na formação de blocos econômicos, como o Mercosul, enfatizando a importância do espanhol na atuação de empresas brasileiros nesse contexto econômico,enfatizandoas novas competências da profissão de SEB, dentre elas: o conhecimento de línguas estrangeiras, especialmente a língua espanhola. Em seguida, abordam-se os aspectos metodológicos e por fim infere-se uma reflexão e discussão acerca da atuação do SEB como agente facilitar em negociaçõesno Mercosul.

Os aspectos descritos neste estudo possibilitaram a reflexão de que com as mudanças na economia mundial e a criação de blocos como o Mercosul, as empresas brasileiras necessitam de profissionais que atendam as exigências do mercado empresarialglobal. Por isso, o SEBestá capacitado para atuar como agente facilitador em negociações nesse bloco econômico, por dispor da fluência na língua espanhola e pelas suas competências gerenciais.

\section{REFERENCIAL TEÓRICO}

\subsection{A GLOBALIZAÇÃO VERSUS A FORMAÇÃO DO MERCOSUL}

De acordo com Lacombe (2003. p, 504),“a globalização se caracteriza pela integração crescente de todos os mercados (financeiros, de produtos, serviços e mão de obra), bem como dos meios de comunicação e de transportes entre todos os países". Desse modo,a aproximação e a competitividade gerada pela globalização possibilitaram mudanças significativas que afetaram diretamente na economia mundial.

A competitividade causada pela aproximação entre organizações internacionais tornou possível a quebra de paradigmas culturais/empresariais, fazendo com que os investimentos tecnológicos fossem aprimorados,no intuito de alcançar a excelência nos serviços. Excelência esta, que lhes permita manter um lugar no mercado global.Lopes (2009, p.182), aponta que: 
"a concorrência local e internacional, consequência da globalização, obriga as empresas a esmerarem-se na qualidade dos seus produtos. E essa procura insistente da qualidade pode ter levado nossas empresas a prepararem-se para vender lá fora”.

Para atender as exigências do mundo globalizado, as organizações tiveram de modificar sua forma de comercialização e produção. Essa integração resultou na formação de blocos econômicos. Segundo Pinheiro (2009, p.137), "o fenômeno da globalização exigiu a cooperação entre países de uma mesma região com o objetivo de fortalecê-los ante o mercado internacional; a essa cooperação chamamos de blocos econômicos". Tendo como objetivo manter relacionamentos políticos e comerciais entre os países-membros, reduzindo a burocracia que envolve os processos de negociações comerciais.

No continente sul-americano, o bloco econômico de maior destaque é o Mercosul, onde Maia (2011, p. 355) descreve que:

O MERCOSUL nasceu em março de 1991, ocasião em que Argentina, Brasil,
Paraguai e Uruguai, reunidos em Assunção, firmaram o Tratado de Assunção. Estes
por sua vez foram seus primeiros integrantes, e tinham como objetivo aumentar as
possibilidades de competitividade dos países do Cone Sul, perante a economia
mundial, garantindo a todos, condições iguais de desenvolvimento.

Trata-se de uma organização internacional, em que todos os membros assumem uma obrigação de ação em conjunto, prevendo a livre concorrência e comercializações empresariais, ou seja, uma união aduaneira, estimulando a livre circulação dos bens, serviços e produtos eliminando algumas restrições alfandegárias.

Nesse cenário global, a atuação de profissionais como SEB, ganha a cada dia maior destaque, por atuarem como assessores em negociações internacionais e pelo domínio de línguas estrangeiras, como o espanhol, por meio de ações que desenvolvam a confiança e a credibilidade entre organizações, fornecedores e clientes.

\subsection{A IMPORTÂNCIA DA LÍNGUA ESPANHOLA PARA COMUNICAÇÃo ORGANIZACIONAL NO MERCOSUL}

Através da globalização e da sua repercussão no universo empresarial, podemos afirmar que a língua estrangeira -(em especial a espanhola - passou a ser considerada como uma ferramenta indispensável para a comunicação entre as empresas integrantes do Mercosul, pois todos os países membros desse bloco, exceto o Brasil, falam espanhol. Dessa maneira, é necessário que as empresas que atuem nesse âmbito, representadas pelos seus agentes comerciais,dominem essa língua, a fim de facilitar suas relações econômicas. 
Sedycias (2005, p.39), aponta que "se quisermos comprar algum produto ou serviço, dos nossos vizinhos sul-americanos, poderemos certamente usar o português. Porém se quisermos que eles comprem os nossos produtos temos defalar a língua deles”. O espanhol é uma língua de grande importância comercial para o mundo. Segundo Bahamond (2012), não se pode esquecer que é a língua materna de aproximadamente 322 milhões de pessoas, oficial em 21 países situados entre as Américas, Europa e África.

Diante desse panorama, as organizações tornaram-se mais exigentes na procura de profissionais que estejam aptos para lidar com suas necessidades empresariais e que estejam preparados para representar suas organizações globalmente. Por isso, faz-se importante à atuação de profissionais como o SEB, que têm assumido um papel estratégico nas organizações por meiodas novas atribuições curriculares que lhes foram acrescentadas durante a progressão de sua carreira.

\subsection{NOVAS COMPETÊNCIAS DO SECRETÁRIO EXECUTIVO}

O mundo empresarial tem passado por várias transformações, sistêmicas, tecnológicas, econômicas, produtivas, logísticas etc. Para atender as necessidades desse mercado, muitas profissões também tiveram de acrescentar novas competências metodológicas a seus perfis, como é o caso do SEB. Veiga (2010) mostra que, antes da regulamentação da profissão, suas atividades não tinham muito envolvimento coorporativo, restringindo-se a: atender telefonemas, agendar visitas e arquivar documentos.

Com as Leis 7.377 e 9.261, Veiga (2010) diz queo cargo do SEB ganhou maior envolvimento corporativo e suas atividadesficaram vinculadas ao marketing, às finanças, à comunicação, liderança, gestão de pessoas, administração individual, grupal e organizacional, posições de assessoria, planejamento estratégico, avaliações de desempenhos, domínio das línguas estrangeiras, negociação comercial, resolução sistemática dos problemas e sua efetivação está profundamente arraigada na participação analítica e intelectual nas organizações. Isso os torna aptos a assumir cargos mais elevados, porque as empresas demandam de profissionais dispostos a administrar bem seus negócios, por meio de estratégias planejadas e bem elaboradas, ações e decisões sobre inovações empreendedoras, por meio de alternativas que proporcionem maior grau de assertividade e dinamismo nas relações comerciais. 
Portanto, para D’Elia et al. (2013, p. 32) “é indiscutível o crescimento dessa profissão, bem como o reconhecimento do mercado, pela sua importância ao atuar como agente facilitador e de resultado junto aos níveis decisórios das empresas em todos os segmentos, no setor privado e público". A comunicação organizacional facilita os processos de decisões e negociações empresariais, tanto no cenário nacional quanto internacional. Segundo Bonde (2009, p. 14), “o secretário passou a ser um cogestor, ou seja, continua auxiliando nas tarefas diárias, porém com mais envolvimento intelectual, em uma gestão exercida em parceria com outras pessoas".

Como já visto, o Mercosul possibilitou aos países-membros maior aproximação comercial, concorrendo permanentemente com as empresas de outros países, a partir do processo de internacionalização. Nesse caso em especial, o domínio do espanhol, torna-se de fundamental importância, tanto para o conhecimento do mercado, quanto para as oportunidades econômicas, além das experiências proporcionadas pelos negócios realizados.

Conforme Neiva e D’Elia (2009, p.55), “cada vez mais os executivos precisam de um profissional parceiro, com uma visão global, para que a ação no seu departamento, na sua agência, possa fluir, naturalmente, dentro da qualidade e velocidade exigida pelo mercado".

O SEB, a partir das novas competências que lhe foram atribuídas, pode ser visto como o profissional ideal para atuar nesse panorama (Mercosul), uma vez que dentre suas novas atribuições, estão o conhecimento de línguas estrangeiras, como o espanhol, e sua função corporativa de comunicador e negociador organizacional.

\section{PROCEDIMENTOS METODOLÓGICOS ADOTADOS NA PESQUISA}

Essa investigação tem por finalidade conduzir seus leitores a uma discussão sobre questões relacionadas à atuação do profissional de Secretariado Executivo Bilíngue. Para tanto, propõe uma reflexão a respeito da participação desse profissional em empresas que atuam no Mercosul, bloco econômico que contribui para o crescimento e transformação dos países que o compõem.

Quanto à metodologia utilizada, trata-se de uma revisão bibliográfica, realizada a partir de estudos desenvolvidos, que não fornecem apenas informações sobre o que já foi publicado, mas sim, uma apreciação crítica do material consultado. Para a elaboração deste artigo, optou-se pelo método dedutivo-exploratório, tendo como principal finalidade segundo Gil (2008, p.27), “desenvolver e esclarecer e modificar conceitos e ideias, tendo em vista a formulação de problemas mais precisos ou hipóteses pesquisáveis para estudos posteriores. Revista de Gestão e Secretariado - GeSec, São Paulo, v. 6, n. 3, p 117-128,Set./Dez. 2015. 
Com o objetivo de proporcionar visão geral, de tipo aproximativo, acerca de determinado fato". O artigo trouxe informações importantes relacionadas à atuação do profissional de SEB, contribuindo para maior aprofundamento do conhecimento sobre a globalização e seus reflexos no setor empresarial.

\section{REFLEXÃO E DISCUSSÃO: O SEB COMO AGENTE FACILITADOR EM NEGOCIAÇÕESDOMERCOSUL}

O presente artigo trouxe alguns elementos para mostrar como a globalização influenciou o desenvolvimento econômico eprovocou mudanças significativas no cenário socioeconômico mundial, por meio da formação de blocos comerciais como o Mercosul.

Diante de tais mudanças, evidenciou-se a necessidade de que tanto as empresas brasileiras quanto os profissionais, devem estar mais qualificados para bem atender as necessidades desse novo mercado, cujo domínio da língua espanhola é um fator primordial para alavancar as negociações entre as organizações atuantes neste bloco, por meio dos agentes que nelas atuem.

Tendo em vista que parte dos negócios empresariais do Brasil ocorre entre países hispanos (países das Américas e Espanha), o domínio do espanhol pode ser considerado uma vantagem competitiva para as organizações, tido como uma ferramenta que amplia o nível conhecimento e comercialização estratégica, através de diálogo, discussões e compartilhamento de experiências que permitam que as organizações alcancem seus resultados, mediante a possibilidade de novas formas de investimentos econômicos internacionais.

Nesse esteio, analisar a estrutura apropriada das comercializações a serem realizadas por meio de controle gerencial e do sistema de informação, acompanhamento das atividades logístico-produtivas, guiando a organização em direção a padrões viáveis de novas atividades em um ambiente caracterizado por mudanças, são atividades influenciadas pela atuação de profissionais como o SEB. Isto porque eles dominam, segundo D'Elia et al. (2013), duas ou mais línguas estrangeiras, como o espanhol, habilidade que se destaca entre as suas competências profissionais, levando-os a atuarem como agentes facilitadores da comunicação e negociação entre as empresas internacionais.

Em estudo realizado, Santos (2012) mostra que no seu campo de trabalho o profissional de SEB naturalmente irá se deparar com uma realidade organizacional de 
interagir com diversos países sobre os mais diferentes produtos e serviços. Para tanto, uma boa fluência oral, de escrita e de leitura (habilidades comunicacionais) em línguas estrangeiras, torna-se imprescindível, favorecendo, substancialmente, os processos de negociação e a tomada de decisões corretas cabíveis.

Entendendo a importância econômica e geopolítica do Mercosul, enquanto bloco que proporcionou uma aproximação comercial e cultural entre as nações sul-americanas, a principal contribuição deste estudo reside em ampliar o conhecimento sobre as competências do SEB, bem como a necessidade empresarial pela busca de profissionais aptos a estabelecerem uma relação comercial sustentável entre as empresas que atuam neste contingente (Cielo et al.,2010). Com isso, poderão ser encontrados novos caminhos em direção à perenidade e ao desenvolvimento econômico dessas organizações. Caminhos que aumentam a responsabilidade do SEB na participação dos resultados produtivos, por meio da sua visão global e capacidade intelectual para delinear problemas e implantar ações apropriadas, que encorajem ao desenvolvimento de posturas globais nas organizações onde porventura atuem.

Contudo, o inglês é a língua mais falada no mundo dos negócios, porém ficou provado que aprender espanhol não se trata apenas de um diferencial competitivo, mas de uma necessidade profissional e empresarial, já que os clientes e investidores fronteiriços ou não com o Brasil, em sua maioria falam essa língua.

\section{CONSIDERAÇÕES FINAIS}

Considerando que tanto as organizações, quanto os profissionais, devem sempre buscar alguma forma de aperfeiçoamento, no sentido de qualificar-se perante o mercado globalizado, foi possível destacar a necessidade empresarial que atenta para aprendizagem ou aperfeiçoamento na língua espanhola, por parte dos brasileiros, no que diz respeito ao Mercosul. Essa necessidade está evidenciada pelas possíveis estratégias a serem utilizadas pelo profissional de SEB, relacionadas à cogestão, no quesito comunicação e negociação. Nesse panorama em que as organizações competem, exige-se que os profissionais atendam às suas necessidades econômicas perante o mercado global.

Buscando sempre manter a excelência profissional, o SEB está habilitado para atuar em nível nacional e internacional, atendendo os pré-requisitos expectados pelas organizações, de forma a assessorar eficientemente dirigentes de empresas públicas ou privadas, pelo domínio de línguas estrangeiras, uma vez que as instituições empresariais e governamentais Revista de Gestão e Secretariado - GeSec, São Paulo, v. 6, n. 3, p 117-128,Set./Dez. 2015. 
de âmbito nacional e internacional têm sido criteriosamente seletivas em relação à composição de seus quadros de funcionários.

Conforme Cielo et al. (2010) e Santos (2012), dentre as suas competências teóricometodológicos, destacam-se o domínio de línguas estrangeiras,o que lhes permite não apenas atuar como assessor, mas também ocupar o cargo de tradutor, demonstrando a importância de sua posição nos momentos de maior expressão da empresa perante a negociação comercial internacional. Dentro desse contexto, o currículo do curso de SEB possui grande relevância no que diz respeito ao conhecimento nas línguas estrangeiras.

Como sugestões para novas linhas de pesquisas científicas, este estudo aponta para a necessidade de que sejam realizadas, pesquisas exploratórias (de campo) por meio de entrevistas e questionários, aplicáveis aos gestores e empresas atuantes no âmbito internacional (Mercosul), a fim de avaliar suas perspectivas e estratégias comerciais quantitativamente e qualitativamente, por meio dos métodos observacional e comparativo que corroboram para atingir os objetivos econômicos organizacionais.

Do exposto, no âmbito Mercosul, faz-se necessário que os profissionais brasileiros quanto às organizações que porventura almejem atuar no ambiente internacional comercial, dominem a língua espanhola, a fim de romper com a maior barreira que nos separa dos nossos vizinhos, "a língua", e dessa forma facilitar o desenvolvimento sócio econômico que favorece o desenvolvimento do Brasil perante o mundo.

\section{Referências}

Bahamond, Waldo Mancilla. (2012). Razões por que você deve aprender espanhol. $\begin{array}{llll}\text { Recuperado em } & 10 & \text { de } & \text { novembro, }\end{array}$ de<http://aprenderespanholesfacil.wordpress.com/tag/aprender-espanhol-2/>. .

Bonde, Maria Thereza. (2009). In Oliveira, Marlene. Manual do profissional de secretariado: secretário como cogestor (2a ed.) Paraná: Editora IBPEX.

Cielo, Ivanete Daga; Schmidt, Carla Maria \& Kühn, Marta Karina Schmitz (2010). A empregabilidade do profissional de Secretariado Executivo: uma análise empírica na Unioeste-campus de Toledo. Revista Expectativa,6( 9).

D’Elia, Bete; Amorim, Magali \& Sita, Mauricio (2013). Excelência no Secretariado: A importância da profissão nos processos decisórios. São Paulo: Editora Ser Mais.

Gil, Antonio Carlos (2008). Métodos e técnicas de pesquisa social (6a ed.). São Paulo: Atlas. 
Lopes, José Vazquez (2009). Comércio exterior brasileiro(9a ed.). São Paulo: Atlas.

Lacombe, Francisco José Masset (2003). Administração: princípios e tendências. São Paulo: Saraiva.

Maia, Jayme de Mariz. (2011). Economia internacional e gestão do comércio exterior(14a ed.). São Paulo: Atlas.

Neiva, Edméa Garcia \& D `Elia, Maria Elizabete Silva (2009). As novas competências do profissional de secretariado (2a ed.). São Paulo: IOB.

Pinheiro, Juliano Lima (2009). Mercado de capitais. São Paulo: Atlas.

Santos, M. P. (2012). Importância do domínio de línguas estrangeiras pelos profissionais de Secretariado Executivo para atuação no mercado de trabalho em tempos de globalização: uma abordagem crítico-reflexiva. Revista de Gestão e Secretariado, 3(1), 94.

Sedycias, J. (2005). Por que os brasileiros devem aprender espanhol? In: Sedycias, J.(Org.) O Espanhol no Brasil: passado, presente, futuro. São Paulo: Parábola.

Veiga, Denize Rachel (2010). Guia de secretariado: técnicas e comportamento(3a ed.). São Paulo: Érica. 